\title{
Variability in the Mozambique Channel Trough and Impacts on Southeast African Rainfallo
}

\author{
Rondrotiana Barimalala, Ross C. Blamey, Fabien Desbiolles, and Chris J. C. Reason \\ Department of Oceanography, University of Cape Town, Rondebosch, South Africa
}

(Manuscript received 5 April 2019, in final form 10 October 2019)

\begin{abstract}
The Mozambique Channel trough (MCT) is a cyclonic region prominent in austral summer in the central and southern Mozambique Channel. It first becomes evident in December with a peak in strength in February when the Mozambique Channel is warmest and the Mascarene high (MH) is located farthest southeast in the Indian Ocean basin. The strength and the timing of the mean MCT are linked to that of the cross-equatorial northeasterly monsoon in the tropical western Indian Ocean, which curves as northwesterlies toward northern Madagascar. The interannual variability in the MCT is associated with moist convection over the Mozambique Channel and is modulated by the location of the warm sea surface temperatures in the south Indian Ocean. Variability of the MCT shows a strong relationship with the equatorial westerlies north of Madagascar and the latitudinal extension of the MH. Summers with strong MCT activity are characterized by a prominent cyclonic circulation over the Mozambique Channel, extending to the midlatitudes. These are favorable for the development of tropical-extratropical cloud bands over the southwestern Indian Ocean and trigger an increase in rainfall over the ocean but a decrease over the southern African mainland. Most years with a weak MCT are associated with strong positive south Indian Ocean subtropical dipole events, during which the subcontinent tends to receive more rainfall whereas Madagascar and northern Mozambique are anomalously dry.
\end{abstract}

\section{Introduction}

Climate variability over southern Africa is driven by a complex interaction between large-scale climate forcings such as El Niño-Southern Oscillation (ENSO), regional sea surface temperature (SST) patterns, and regional atmospheric circulation systems [e.g., the Angola low (AL) and Botswana high (BH)] at various temporal scales (Lindesay 1988; Nicholson and Kim 1997; Reason et al. 2000; Behera and Yamagata 2001; Reason and Rouault 2002; Reason 2001, 2016; Blamey et al. 2018; Driver et al. 2019; Desbiolles et al. 2018; Crétat et al. 2019). An important regional circulation system, although not well understood, is the Mozambique Channel trough (MCT), characterized by a low pressure area over the central and southern Mozambique Channel during austral summer

Supplemental information related to this paper is available at the Journals Online website: https://doi.org/10.1175/JCLI-D-190267.s1.

Corresponding author: Rondrotiana Barimalala, rondrotiana. barimalala@uct.ac.za
(Cook et al. 2004; Munday and Washington 2017). The MCT is found to be generated by a dynamical adjustment of the easterlies flowing over the topography of Madagascar and may also be sustained by local air-sea interaction due to the relatively warm SST over the channel (Barimalala et al. 2018).

The MCT is located near the source of the south Indian Ocean convergence zone (SICZ; Cook 2000), a dominant driver of southern African rainfall (Cook 2000; Lazenby et al. 2016), and thus modulates the moisture transport within the SICZ as well as the mean rainfall over the subcontinent (Barimalala et al. 2018). The role of the MCT in the distribution and frequency of rainfall events is however not well understood. Cook et al. (2004) analyzed wet and dry spells over South Africa and found that a cyclonic feature off the east coast could drive moisture away from the mainland, thus leading to a decrease in rainfall. By using output from phase 5 of the Coupled Model Intercomparison Project (CMIP5), Munday and Washington (2017) found that models with weak MCT tend to contain a strong positive rainfall bias over southern Africa. They indicate that enhanced direct moisture inflow from the southwestern Indian Ocean (SWIO) 
strengthens the Angola low and favors the increase in rainfall over the subcontinent, if the MCT is weak. In a recent study, Barimalala et al. (2018) used a set of idealized numerical experiments with the Weather Research Forecasting (WRF) regional model in which the topography of Madagascar was flattened. They found that a flattening of the topography over Madagascar results in weakening of the MCT. They also confirmed that a weak (strong) MCT strengthens (weakens) the SICZ, and hence favors (weakens) the transport of moisture from SWIO toward mainland southern Africa, leading to an increase (decrease) in local rainfall. In addition, these authors proposed that the persisting rainfall bias over southern Africa in the state-of-the art climate models (e.g., Munday and Washington 2017, 2018) could be due to a poor representation of the MCT in those models. Moreover, recent work by Pascale et al. (2019) shows that a weakening of the MCT leads to stronger northerly moisture flux from the tropical Indian Ocean penetrating to the African mainland, which then strengthens the Angola low and triggers an increase in regional rainfall.

These studies indicate that the MCT likely plays a key role in southern African climate variability. However, despite being a prominent circulation in the area, the mean state and variability of the trough, to our knowledge, have never thoroughly investigated. Moreover, little to no work has been focused on the impacts of the MCT on southern African rainfall, especially at time scales other than climatology. Thus, the main objective of this study is to investigate the mean state, annual cycle, and interannual variability of the MCT and its relationships with regional rainfall.

\section{Data and methodology}

\section{a. Data}

The data used to analyze the MCT seasonality and variability are monthly low-level (at $850 \mathrm{hPa}$ ) relative vorticity, geopotential height, specific humidity, total cloud cover, wind, and mean sea level pressure (MSLP) represented in the ERA-Interim reanalysis (Dee et al. 2011) for the period of 1980-2017. These data have a horizontal resolution of $0.75^{\circ} \times 0.75^{\circ}$. Rainfall data were obtained from the Climate Hazards Group Infrared Precipitation with Stations (CHIRPS) data at $0.05^{\circ} \times 0.05^{\circ}$ horizontal resolution (Funk et al. 2015), available for 1981-2017, and from the Climate Prediction Center Merged Analysis of Precipitation (CMAP; Xie and Arkin 1997), at $1.25^{\circ} \times 1.25^{\circ}$ horizontal resolution, for $1980-2017$ to investigate the link between the MCT and regional rainfall variability. Included in the analysis are SST data from the Hadley Centre Global Sea Ice and Sea Surface Temperature dataset (HadISST; Rayner et al. $2003 ; 1^{\circ} \times 1^{\circ}$ horizontal resolution) and NOAA interpolated outgoing longwave radiation (OLR) at the top of the atmosphere (Liebmann and Smith 1996; $2.5^{\circ} \times 2.5^{\circ}$ horizontal resolution).

\section{b. Methodology}

In sections $3 \mathrm{a}$ and $3 \mathrm{~b}$, we analyze the annual cycle and interannual variability of the trough. The MCTrv index is defined as the area averaged of the relative vorticity at $850 \mathrm{hPa}$ over the southern Mozambique Channel (Barimalala et al. 2018). For comparison, we also make use of the 850-hPa geopotential height (MCThgt) averaged over the same area, as an alternative index to characterize the annual cycle and variability of the MCT. An empirical orthogonal function (EOF) analysis is conducted to confirm that these MCT indices represent the dominant mode of variability in the channel.

To investigate the processes that drive the variability in the MCTrv, analysis of the vorticity budget is performed in section $3 \mathrm{~b}$, with the corresponding equation described in the online supplemental material.

An analysis on the links between the MCT and the northeast (NE) monsoon flow that exists in the austral summer across the tropical western Indian Ocean is also performed. In doing so, four indices are defined to characterize the flow from the tropical western Indian Ocean toward eastern Africa. They are defined as follows:

(i) $\mathrm{VN}$, mean meridional wind averaged over $40^{\circ}-50^{\circ} \mathrm{E}$ at $1^{\circ} \mathrm{S}$ (Fig. 1b);

(ii) VS, same as $\mathrm{VN}$ but farther to the south, at $9^{\circ} \mathrm{S}$ (Fig. 1b);

(iii) UW, mean zonal wind that penetrates into southern African mainland (Fig. 1b, between $1^{\circ}$ and $12^{\circ} \mathrm{S}$ at $38^{\circ} \mathrm{E}$ ); and

(iv) UE, mean zonal wind over the northern Mozambique channel that flows toward Madagascar (Fig. 1b, between $9^{\circ}$ and $15^{\circ} \mathrm{S}$ at $44^{\circ} \mathrm{E}$ ).

The roles of large-scale forcing and regional circulation patterns on the interannual variability of the MCT are analyzed in section $3 \mathrm{~d}$ by using the following indices:

- NINO34, area averaged SST anomaly within $190^{\circ}-$ $240^{\circ} \mathrm{E}, 5^{\circ} \mathrm{S}-5^{\circ} \mathrm{N}$ (Trenberth and Stepaniak 2001).

- The oceanic Niño index (ONI) from the National Centers for Environmental Prediction is used to determine the presence of El Niño/La Niña events. Such an event is characterized by a 3-month running mean of NINO34 that exceeds the threshold $\pm 0.5^{\circ} \mathrm{C}$ for five consecutive overlapping seasons.

- Indian Ocean dipole (IOD), the SST anomaly difference between one pole averaged over $50^{\circ}-70^{\circ} \mathrm{E}$, 

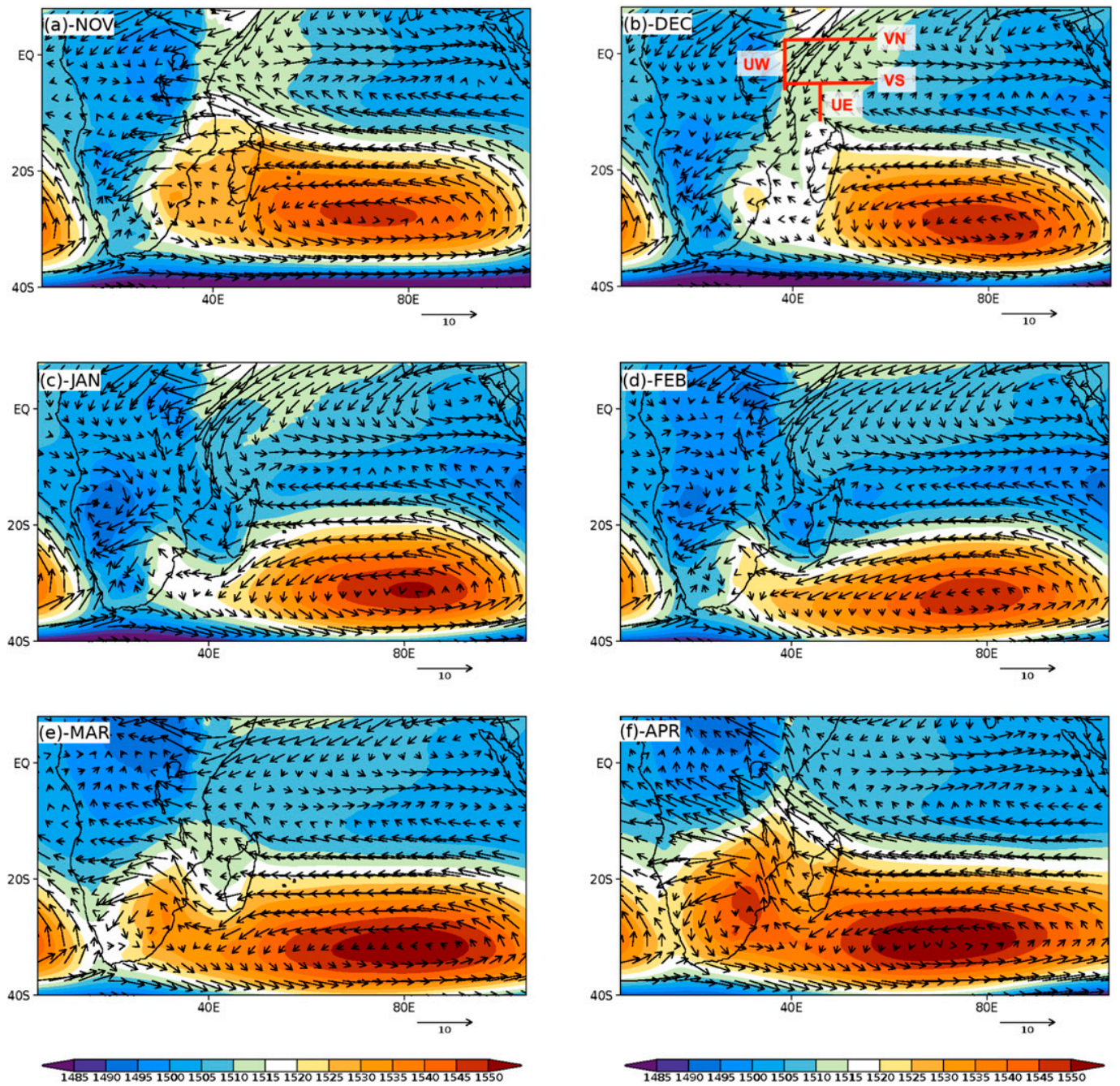

$\frac{1}{1485} 1490149515001505151015151520152515301535154015451550$

14851490149515001505151015151520152515301535154015451550

FIG. 1. (a)-(f) Monthly $850-\mathrm{hPa}$ wind (vectors; $\mathrm{m} \mathrm{s}^{-1}$ ) and geopotential height (shaded; $\mathrm{m}$ ) from November to April, respectively. In (b), the lines demarcate where the zonal/meridional flow linked to the NE monsoon is determined (see text). UW refers to zonal wind penetrating into mainland, UE is zonal wind recurving toward Madagascar, VN is cross-equatorial northeasterly monsoon, and VS is meridional wind reaching the north of Madagascar.

$10^{\circ} \mathrm{S}-10^{\circ} \mathrm{N}$ and the other over $90^{\circ}-110^{\circ} \mathrm{E}, 10^{\circ} \mathrm{S}-0^{\circ}$ (Saji et al. 1999);

- Indian Ocean subtropical dipole (IOSD), the SST anomaly difference between one pole averaged over $55^{\circ}-67^{\circ} \mathrm{E}, 27^{\circ}-37^{\circ} \mathrm{S}$ and the other over $90^{\circ}-110^{\circ} \mathrm{E}, 18^{\circ}-$ $28^{\circ} \mathrm{S}$ (Behera and Yamagata 2001).

- Mascarene high (MH), area averaged MSLP within $40^{\circ}-110^{\circ} \mathrm{E}$ and $15^{\circ}-40^{\circ} \mathrm{S}$.

- Southern annular mode (SAM), the Marshall SAM index, based on the zonal pressure difference between the latitudes of $40^{\circ}$ and $65^{\circ} \mathrm{S}$ (Marshall 2003).

- Botswana high (BH), average of 500-hPa geopotential height within $19^{\circ}-23^{\circ} \mathrm{S}, 16^{\circ}-21^{\circ} \mathrm{E}$ (Driver and Reason 2017).

- Angola low (AL), average of $850-\mathrm{hPa}$ geopotential height within $11^{\circ}-19^{\circ} \mathrm{S}, 14^{\circ}-25^{\circ} \mathrm{E}$.
The lead-lag correlations used in section $3 \mathrm{~d}$ are computed as follows: the MCT index is fixed at January-March (JFM) while the SST indices are shifted one month at a time. Positive lags are therefore indicative of the MCT leading the SST climate mode indices and vice versa for negative lags. For example, lag $=-1$ means the anomaly for the months of December-February (DJF) is used for the SST, whereas the SST anomaly for February-April is used for lag $=+1$.

Composite analyses are also used to analyze the link between MCT and southern African rainfall and the corresponding mechanisms. The two-tailed nonparametric Monte Carlo bootstrap test is applied for statistical significance in all composites. 

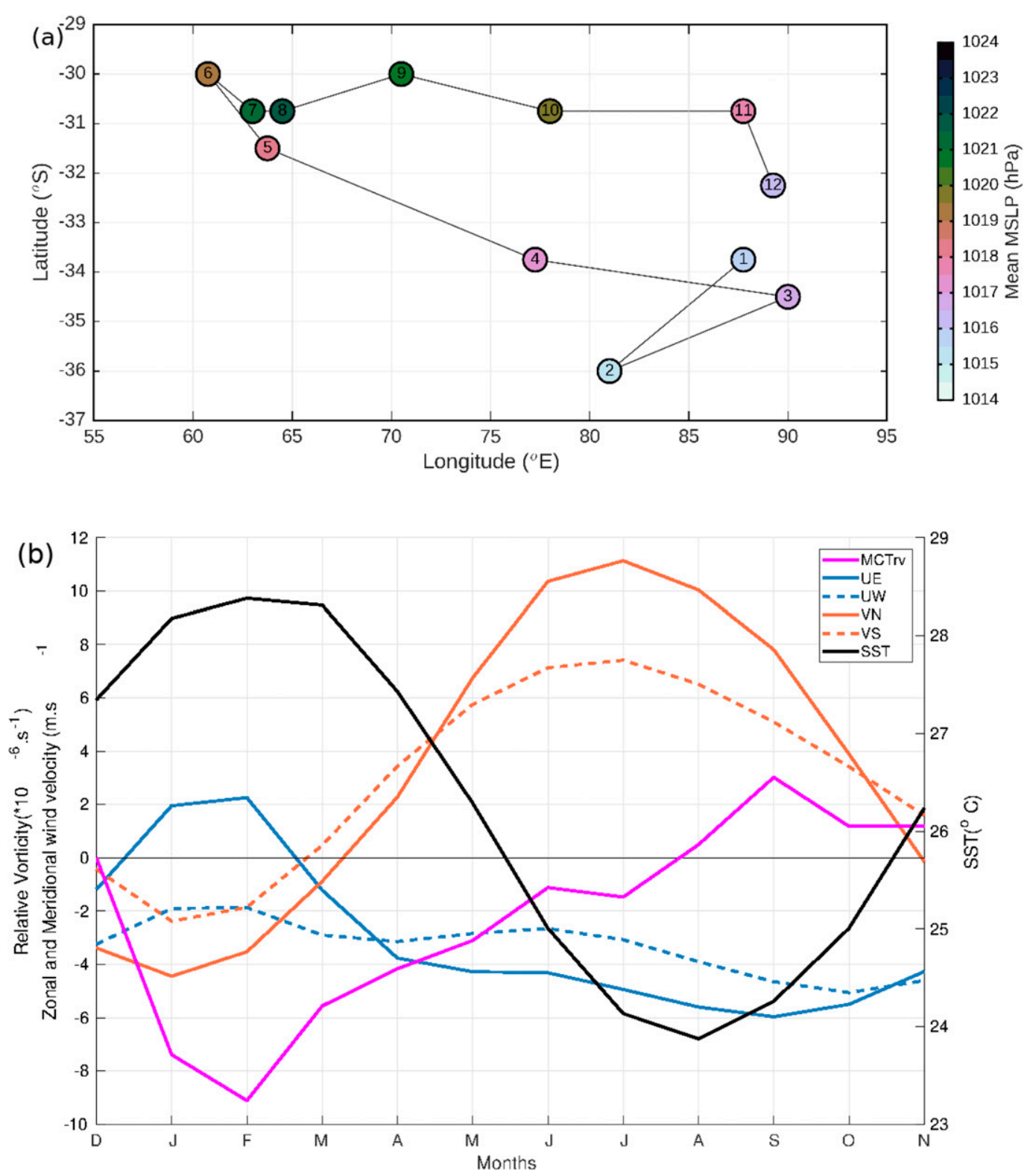

FIG. 2. (a) Annual cycle of the Mascarene high (colors) and geographical position of the center. The numbers in the circles correspond to the months. (b) MCTrv, zonal wind penetrating into mainland (UW), zonal wind recurving toward Madagascar (UE), cross-equatorial northeasterly monsoon (VN), and meridional wind reaching the north of Madagascar (VS), and SST over the Mozambique Channel.

\section{Results}

\section{a. MCT annual cycle}

Figure 1 shows the monthly climatology of $850-\mathrm{hPa}$ geopotential height and wind from ERA-Interim from November to April (austral summer) for the period of 1980-2017. The low pressure area, associated with cyclonic circulation over the southern and central Mozambique Channel (the MCT) is identifiable from December to April but is strongest during JFM. The MCT, along with the Angola low, sits in between two prominent subtropical high pressure systems, the MH and the South Atlantic high pressure or the St. Helena high. From April to September, when the MH and St. Helena high are merged with the continental high located over southern Africa, the MCT and AL are relatively weak (not shown). From October, the MH weakens and moves farther southeast over the south Indian Ocean basin (Fig. 2a), while the MCT (AL) strengthens until it reaches its peak in February (January). The annual cycle of the MCTrv 
shows negative vorticity from December to July, confirming the presence of the trough, which is particularly strong during JFM (Fig. 2b). The MCThgt is also consistent with MCTrv in which JFM is characterized by a relatively low height compared to other months. Moreover, a vertical transect through the MCT shows that during JFM the reversal of the zonal flow occurs at a deeper level (between 600 and $400 \mathrm{hPa}$ ) compared to the other months (not shown), confirming the deepening of the trough during these months.

The trough is mostly seen when the wind from the south Indian Ocean flows zonally toward Madagascar, so that it impacts directly on the mountains that run north-south along the island, rather than when the wind blows diagonally to the northwest, such as that during the austral winter (not shown). The role of the low-level easterly flow and interaction with local topography in the formation of the MCT is described in Barimalala et al. (2018). In fact, the onset of the MCT in December (Fig. 1b) takes place after the monsoonal winds off the southern Tanzania/northern Mozambique coast reverse from being southeasterly to northeasterly. After reaching its peak in February, the trough weakens gradually while the monsoon reverses back to being southeasterly in March-April (Fig. 1). During January and February, the NE monsoon flowing across the equator is divided into three main branches. Part of the monsoon penetrates into the southern African mainland whereas the remaining flows along the Tanzanian coast before splitting into two westerly branches. The first one curves toward the Indian Ocean just south of the equator, while the second penetrates farther to the south before curving toward northwestern Madagascar. The latter feeds the northern edge of the cyclonic circulation around the MCT. The trough is strongest when there are monsoonal westerlies in the northern Mozambique Channel. In fact, Pascale et al. (2019) suggest a link between northerly moisture flux penetrating to the African mainland from the Indian Ocean and the strength of the MCT. To investigate the role of the NE monsoon on the MCT mean state, the annual cycles of the zonal and meridional components of the wind flowing from the western Indian Ocean toward mainland southern Africa and Madagascar are analyzed (Fig. 2b; indices are defined in section 2). Positive (negative) values in Fig. $2 b$ indicate southerlies (northerlies) for the meridional components and westerlies (easterlies) for the zonal components.

Throughout the year, VN and VS (meridional winds flowing across the equator) have almost the same phasing in seasonality (Fig. 2b), which is characterized by northerly flow between December and February (extended through to March for VN) and southerly flow during the remaining months, but with magnitudes noticeably larger near the equator at VN than at VS. On the other hand,
UW (zonal wind flowing toward mainland Africa) stays negative throughout the year with a minimum amplitude in January and February, the months when UE consists of positive values (i.e., more westerlies flowing toward Madagascar). These plots confirm that when the MCT is at its peak, the NE monsoon penetrates farther into the northern Mozambique Channel, after which it curves toward northwestern Madagascar and becomes a northwesterly flow which feeds the circulation around the MCT.

It is worth noting that the peak in intensity of the MCT in late austral summer months (i.e., JFM) occurs around the time large parts of southern Africa receive a maximum in precipitation (i.e., January and February). Although not as pronounced as in the preceding three months, the region, particularly the northeastern parts, still receives a considerable amount of precipitation in March. The intertropical convergence zone (ITCZ) is located at its southernmost position over the channel during that period. In addition, an area average of monthly SST over the southern and central part of the Mozambique Channel shows that the strongest MCT season also coincides with the warmest SST period in the channel (Fig. 2b), indicating a possible role of the ocean temperature on the mean state of the trough (Barimalala et al. 2018).

\section{b. MCT interannual variability}

From now on, the focus is placed on the JFM season, when the trough is strongest. The MCT indices (MCTrv and MCThgt described in section 2b) display a weak strengthening tendency (statistically insignificant) during the period of study. Although weak, the linear trend is removed from the time series by using a least squares regression technique.

Figure 3a shows the detrended time series of standardized anomalies in the MCT indices for JFM during the 1980-2017 period. The two indices display a strong interannual variability in their intensities and are highly correlated at $r=0.73(p<0.001)$. An empirical orthogonal function analysis of the JFM relative vorticity anomalies over the Mozambique Channel results, in the first mode, in a pattern of negative relative vorticity over the channel (explaining about $29 \%$ of the total variance; not shown), whose principal component is highly correlated to MCTrv with $r=0.74$ ( $p<0.001$; Fig. 3a). The depth in the troposphere at which the reversal of the zonal flow occurs within the MCT is characterized by weak interannual variability (ratio between standard deviation and mean depth $\sim 0.3$ ) and is barely correlated to the MCT indices, suggesting that the MCT interannual variability is only relevant at lower atmospheric levels.

For the remainder of this study, we will mainly use the MCTrv to characterize the trough, with MCThgt only used for comparison. 

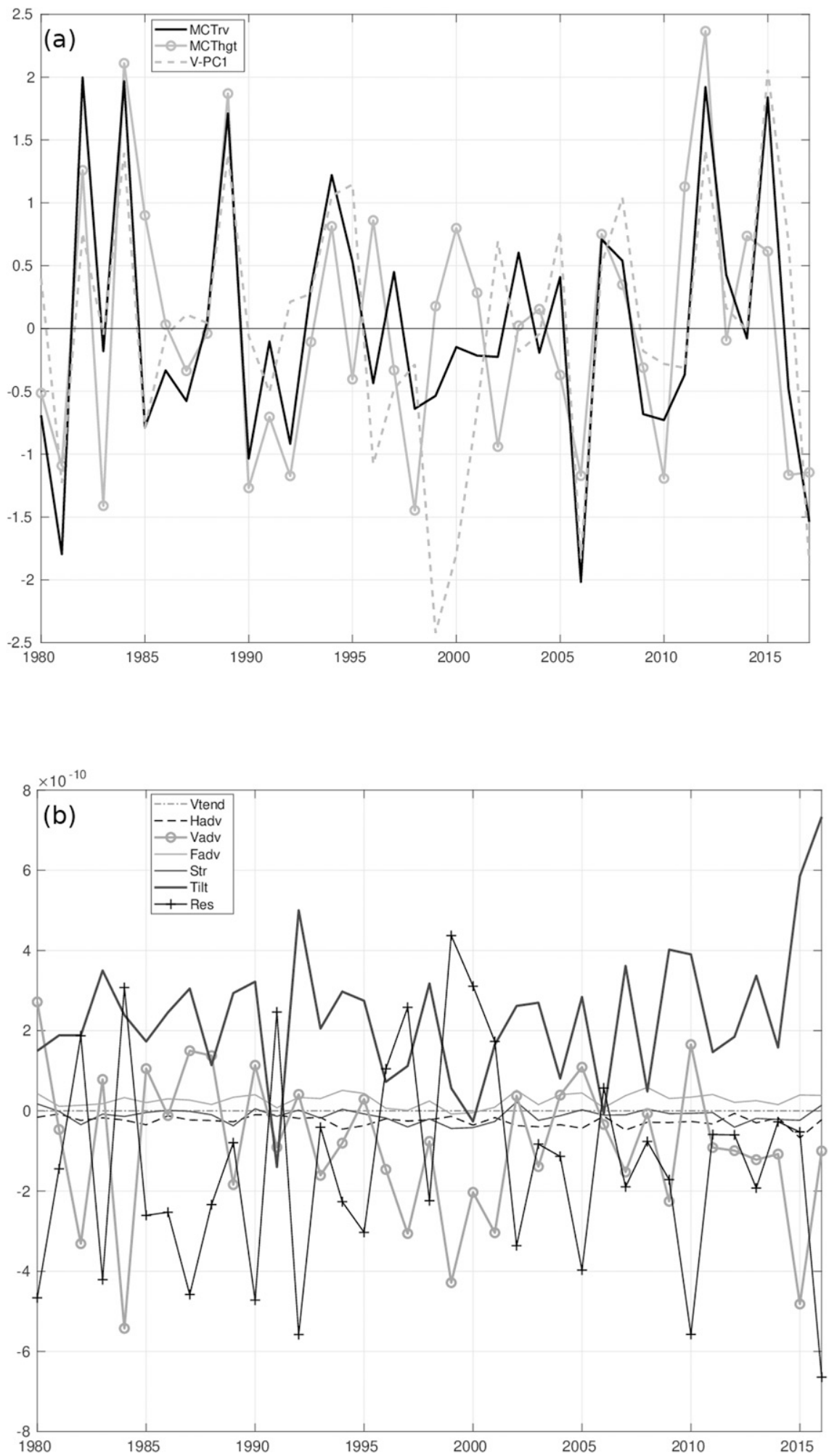

FIG. 3. (a) Time series of the standardized MCT anomaly for JFM 1980-2017: relative vorticity index (MCTrv), geopotential height index (MCThgt), and first principal component from the relative vorticity EOF analysis (V-PC1). (b) Different terms of the JFM vorticity budget: vorticity tendency (Vtend), horizonal advection (Hadv), vertical advection (Vadv), planetary advection (Fadv), stretching term (Str), tilting term (Tilt), and residual term (Res). 

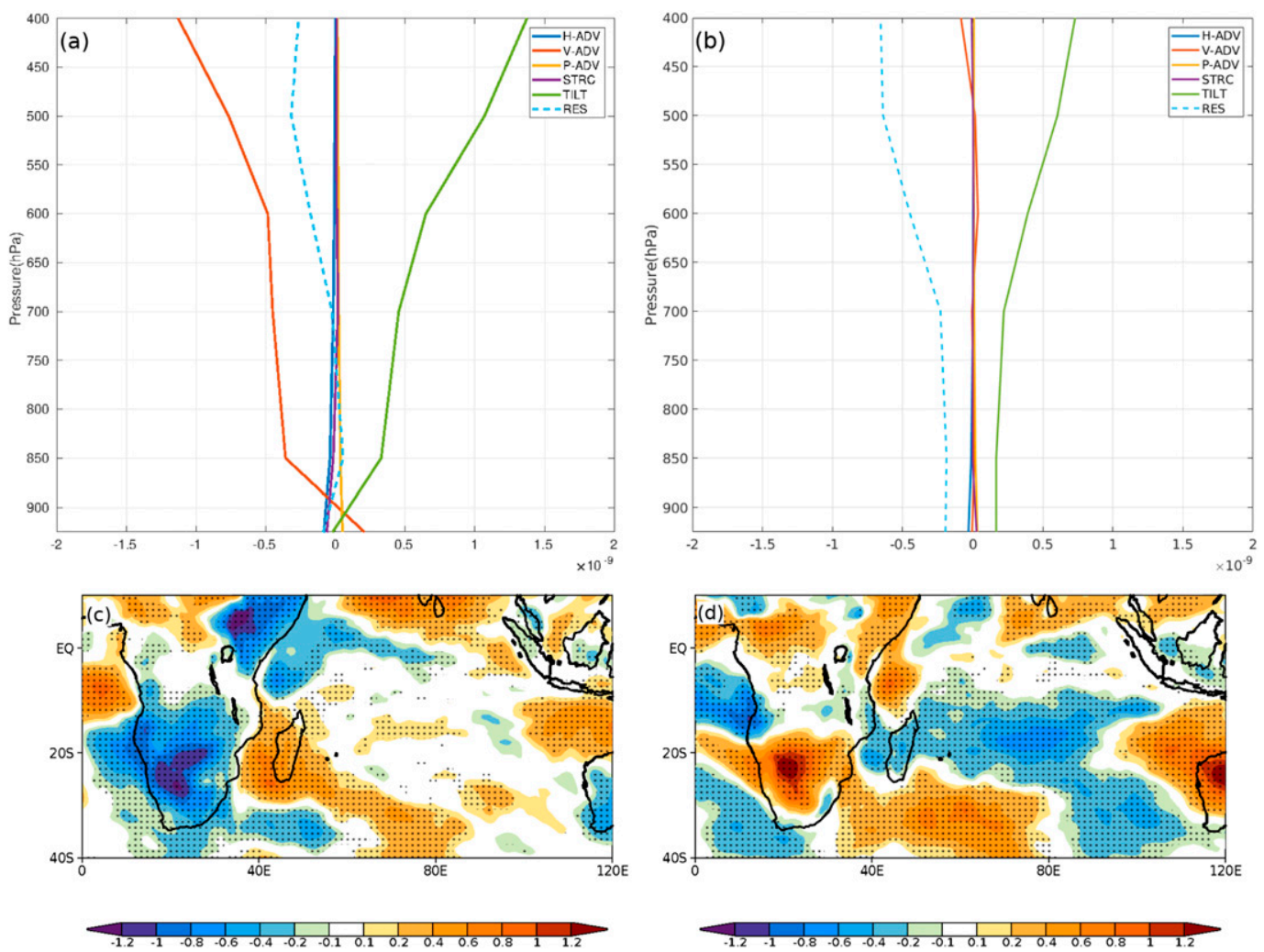

FIG. 4. Composite anomaly of different terms of the (top) JFM vorticity budget and (bottom) specific humidity at $850 \mathrm{hPa}\left(10^{-3} \mathrm{~kg} \mathrm{~kg}^{-1}\right)$ during (a),(c) strong and (b),(d) weak MCT years. Vorticity budget terms: vorticity tendency (Vtend), horizontal advection (Hadv), vertical advection (Vadv), planetary advection (Fadv), stretching term (Str), tilting term (Tilt), and residual term (Res). Stippling on the maps shows significance at or above $95 \%$ confidence level using two tailed nonparametric Monte Carlo bootstrap statistical significance test.

An evaluation of the different terms in the vorticity budget equation is performed in order to investigate the physical processes that generate the interannual variability of the MCT. The vorticity equation in pressure coordinates and explanations of the different terms are detailed in the online supplemental material. The area average of each term in the vorticity equation within the MCT box $\left(35^{\circ}-44^{\circ} \mathrm{E} ; 16^{\circ}-26^{\circ} \mathrm{S}\right)$ at $850 \mathrm{hPa}$ for the period of study is shown in Fig. 3b. Overall, the vorticity tendency is relatively weak and is dominated by a balance between the vertical advection, tilting, and residual terms. These indicate a strong influence of local forcing (from the three dominant terms in the vorticity budget) on the MCT variability.

By using the criterion of at least one standardized $( \pm 1 \sigma)$ departure from the mean on the MCTrv index, the years of 1982, 1984, 1989, 1994, 2012, and 2015 are identified as strong MCT summers (large negative vorticity anomalies), whereas 1981, 1990, 2006, and 2017 are considered weak MCT summers. The vertical profiles of the different terms from the vorticity budget during strong/weak MCT years show that the vertical advection term is reduced to almost zero when MCT is weak (Figs. 4a,b). We also looked at the composites of specific humidity $q$ at $850 \mathrm{hPa}$. Positive anomalies are found over the Mozambique Channel during strong MCT years and vice versa for weak years (Figs. 4c,d). Together with the vorticity budget, these results suggest that the MCT variability may be associated with moist convection over the Mozambique Channel.

A composite analysis of the SST anomalies in the Indian Ocean region is conducted in order to investigate the impacts of regional SST variability on the trough. Stippling in all the composite maps shows significance at or above the $95 \%$ confidence level using a two-tailed nonparametric Monte Carlo bootstrap statistical significance test. Strong MCT years are associated with a dipole-like SST anomaly pattern in the Indian Ocean over about $8^{\circ}-$ $40^{\circ} \mathrm{S}$, in which cold anomalies occur over the western half and warm anomalies over most of the eastern half. Cool anomalies extend over the equatorial region and north Indian Ocean. The strongest cool anomalies occur near the east coast of Africa, in the Mozambique Channel and to the south and southeast of Madagascar (Fig. 5a). 

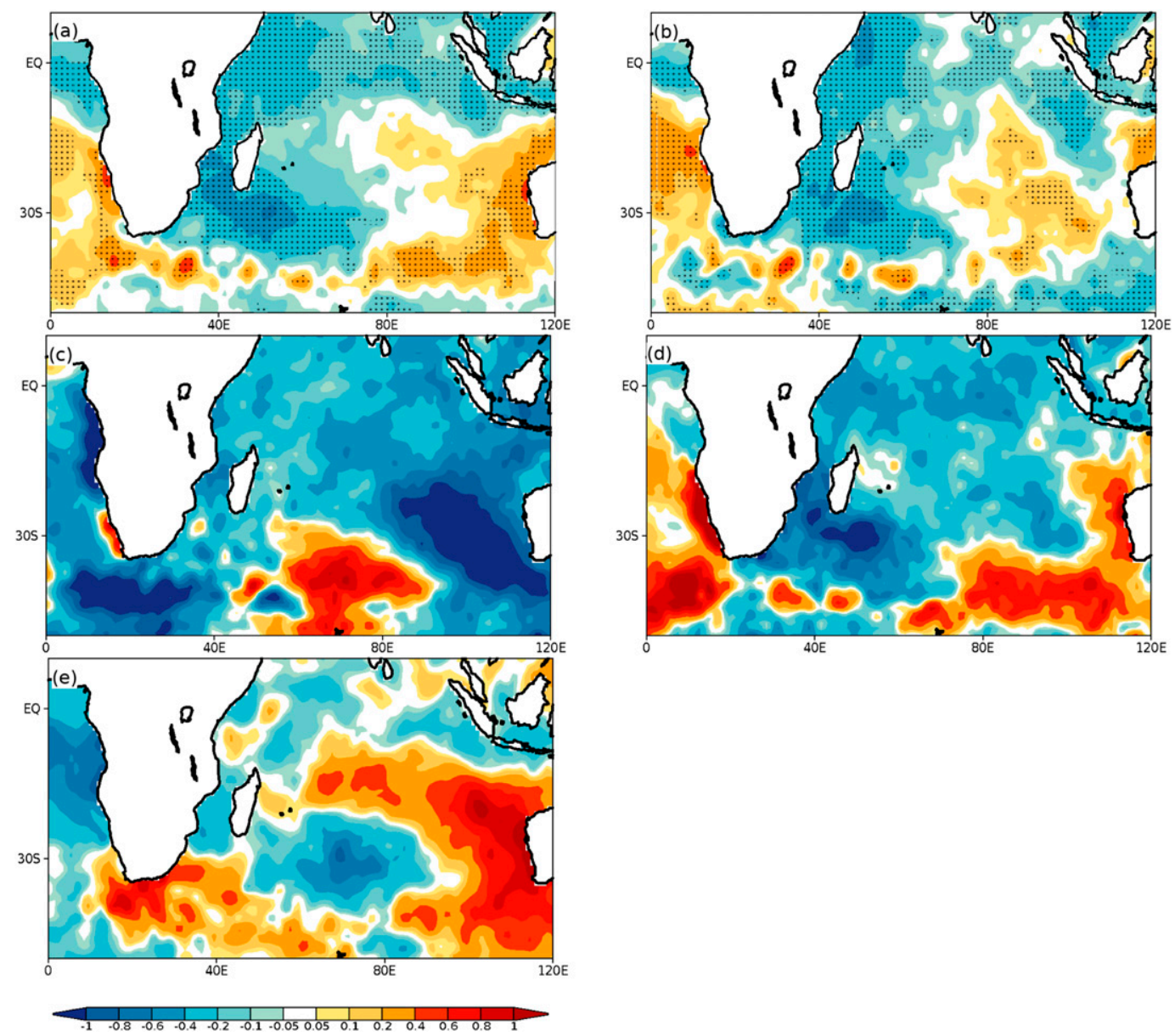

FIG. 5. Composite anomaly of JFM SST $\left({ }^{\circ} \mathrm{C}\right.$ ) during strong MCT years: (a) all strong MCT years included, (b) NoENSO-NoIOSD, (c) 1982, positive IOSD; (d) 1980, La Niña year; and (e) 2012, positive IOSD and La Niña year. Stippling shows significance at or above the $95 \%$ confidence level using a two-tailed nonparametric Monte Carlo bootstrap statistical significance test.

Among the strong MCT years, JFM 1989 and 2012 show strong La Niña conditions based on the ONI classification, whereas 1982 is a strong positive IOSD year. In the following, we categorize the strong MCT years as follows: No Niño-No IOSD (Fig. 5b), positive IOSD (Fig. 5c), and La Niña (Figs. 5d,e). A common pattern of cold SST anomaly is seen in all categories over the western Indian Ocean, extending from north of the equator to the south of Madagascar. Farther to the east, all categories depict warm SST anomalies that differ in their amplitudes and locations. For No Niño-No IOSD and La Niña years, the positive anomalies are located in the southeastern part of the basin, with higher magnitude in the La Niña years. In contrast, the warm SST anomaly is located at the center of the south Indian Ocean for 1982 (Fig. 5d). The cold SST anomaly in the Mozambique Channel is due to enhanced Ekman suction from the cyclonic flow of the MCT winds, which leads to upwelling of deeper and colder water. It is worth noticing that excluding the La Niña and positive IOSD years does not lead to a significant change in SST anomalies over the southwestern Indian Ocean during strong MCT years.

A similar analysis is performed for years considered as weak MCT years $(1981,1990,2006$, and 2017). Over most of the region, the pattern (Fig. 6a) is more or less opposite to the strong MCT composite. However, this is not true for the region immediately east of northern Madagascar or the central/eastern equatorial parts of the basin. The apparent dipole in SST anomaly over the south Indian Ocean during weak MCT years is explained by the overlap with strong positive IOSD years (JFM-IOSD index $>1 \sigma$ ), except for 1990 which is neutral IOSD. The three positive IOSD-weak MCT years depict the same pattern as the composite [warm (cold) SST anomaly in the southwest (southeast) Indian Ocean; Fig. 6b], whereas 1990 shows a weak positive anomaly over the Mozambique Channel 

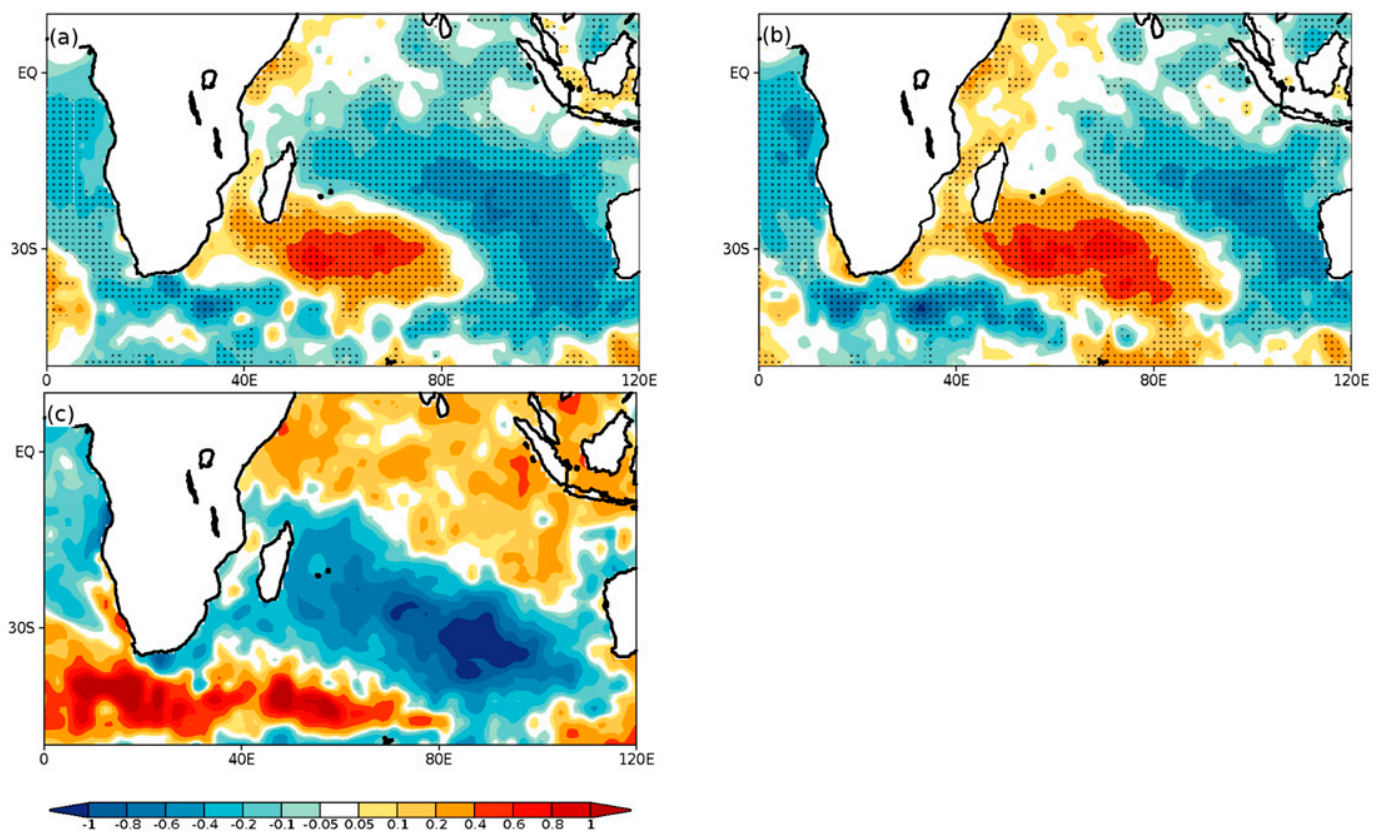

FIG. 6. Composite anomaly of JFM SST $\left({ }^{\circ} \mathrm{C}\right)$ during weak MCT years: (a) all weak MCT years included, (b) positive IOSD years, and (c) 1990, NoENSO-NoIOSD. Stippling shows significance at or above $95 \%$ confidence level using a two-tailed nonparametric Monte Carlo bootstrap statistical significance test.

and cold anomaly in the southern Indian Ocean, between $40^{\circ}$ and $20^{\circ} \mathrm{S}$ (Fig. 6c). It is worth noting that not all strong IOSD summers (e.g., 1982, 1993) show a weak MCT; in fact, 1982 is a strong MCT summer.

For different IOSD years, the location of the positive SST anomaly pattern seems to be associated with the strength of the MCT. If positioned toward coastal South Africa, the MCT is weak, whereas a shift of the positive anomaly toward the center or to the east is associated with a strong MCT. These results suggest that during IOSD years, the MCT signal can be overwhelmed by the warm SST anomaly located closer to southern Africa, which is known to strongly affect southeastern African rainfall (Behera and Yamagata 2001; Reason 2001, 2002).

\section{c. Links between MCT variability and regional circulation}

To investigate the possible role of the NE monsoon on the MCT variability, the JFM standardized anomalies of the wind indices (same as those used in section 3a) for the 38 -yr period of study are used. In the following, all correlation analyses are performed with the detrended time series of the corresponding variables. The correlation between MCTrv and VN is $r=-0.65$ and $r=0.59$ for MCTrv and VS $(p<0.001$ for both, statistically significant at $99.9 \%)$. The MCTrv and UW indices are correlated at $r=-0.45(p=0.0046)$, whereas $r=0.66$ $(p<0.001)$ for the MCTrv and UE (significant at
99.9\%). The correlations between MCThgt and the wind indices show almost the same results. These results suggest that the MCT interannual variability is strongly linked to the strength of the NE monsoonal flow that crosses the equator, penetrates into the northern Mozambique Channel, and then curves as a northwesterly flow toward northwestern Madagascar. The correlations with the NE flow also could imply a link between MCT and other regional circulation such as the $\mathrm{AL}$ and $\mathrm{BH}$ systems. These circulations are known to influence southern Africa summer rainfall (e.g., Cook et al. 2004; Reason 2016; Driver and Reason 2017; Munday and Washington 2017; Howard and Washington 2018; Pascale et al. 2019). Using the same index as Driver and Reason (2017), the links between the MCTrv and BH show no significant correlation $(r=0.27)$. A similar result is found between MCTrv and AL $(r=0.30)$. On the other hand, the MCThgt index is correlated with the $\mathrm{BH}$ and $\mathrm{AL}$ indices at $r=-0.63$ and -0.78 respectively (with $p<0.001$ for both). Given that both the $\mathrm{BH}$ and the AL are strongly modulated by ENSO, which leads to large-scale pressure anomalies across the region (Reason et al. 2000), these relatively high correlation values are not unexpected. The negative correlation between MCThgt and AL is in agreement with Pascale et al. (2019), in which weak MCT is associated with both a strong AL and a strong NE monsoon penetrating to mainland. It is likely that the weaker correlation 
values obtained when by using the MCTrv index could partly be due to the variability in the vorticity being dominated by local forcings. The exact relationship between the MCT and the AL however remains unclear. The modeling results of Barimalala et al. (2018) indicate that a strong MCT could lead to a weak AL and vice versa for a strong AL. Here, the maximum correlation between the two indices occurs at zero lag, whereas the correlations are almost the same when either of the two leads at one month (not shown).

A significant correlation is found between the MCTrv and the MH index $(r=0.34, p=0.036)$ for $1980-2017$. The correlation is considerably higher $(r=0.68, p<$ 0.001 ) between MCThgt and $\mathrm{MH}$, which could result from the strong link between ENSO and MCThgt (discussed later in this section). As shown in section $3 \mathrm{a}$, the mean MCT is strongest when the $\mathrm{MH}$ is positioned toward the southeast of the Indian Ocean basin. Here, the locations of the south/northernmost and east/westernmost limits of the 1017-hPa MSLP contours are used to evaluate the link between MCT and the position of the $\mathrm{MH}$. This contour is essentially the lowest closed contour level around this high pressure system. A shift to the south and to the west in the $\mathrm{MH}$ is considered negative. Note that the location of the center of $\mathrm{MH}$ is not used because it does not fully reflect the zonal or meridional extension of this high pressure system (Morioka et al. 2015). The east/westernmost longitudes (EL/WL) and south/northernmost latitudes (SL/NL) of the JFM averaged 1017-hPa contour are tracked for each year during 1980-2017. Interestingly, MCTrv is only significantly correlated with the meridional shift of the northern limit of reference contour NL, which oscillates between $20^{\circ}$ and $37^{\circ} \mathrm{S}(r=-0.38, p=0.018$, statistically significant at $95 \%)$. The trough is stronger when the northern border of $\mathrm{MH}$ is located more to the south, allowing the easterlies to flow over the high topography of Madagascar and form a lee side vortex in the channel. A more northward position of the MH in JFM would result in stronger southeasterlies flowing toward northern Madagascar and toward the mainland (i.e., a more winter-type circulation; Fig. 1), thereby weakening the cyclonic circulation around the MCT. On the other hand, MCThgt is strongly correlated to both NL and EL $(r=-0.56, p=0.003$ and $r=0.48, p=0.0023$ respectively). The MCThgt-EL correlation could be triggered by the link between $\mathrm{MH}$ and ENSO (discussed in section 3d), given that EL is strongly correlated with ENSO $(r=0.59, p<0.0001)$.

\section{d. Links between MCT and climate modes of variability}

The MCT is located close to the SICZ, which positions itself over southeastern Africa and/or the adjacent ocean and which is known to be modulated by various largescale modes of climate variability, such as ENSO, IOD, and IOSD (Lindesay 1988; Manatsa and Reason 2017; Reason et al. 2000; Behera and Yamagata 2001; Reason 2001; Rowell 2013). To test the existence of connections between the MCT and these modes of variability, a leadlag correlation analysis is performed between the MCT indices for JFM and the corresponding indices of the modes during 1980-2017 (details in section 2).

For a lead or lag of 4 months or less, MCTrv shows no significant correlation with any of ENSO, IOD, or IOSD but does appear to be correlated with SAM (Fig. 7a). In fact, there is no significant correlation between NINO34 and MCTrv for any lag between -12 or +12 months. The IOD is barely significantly correlated with the MCT when preceded by more than 5 months. On the other hand, the IOSD shows a statistically significant negative correlation with MCTrv, both for when the IOSD leads for 4 months and when the MCT leads by more than 7 months. The 4month lagged negative correlation with IOSD suggests that the gradient in SST anomaly over the subtropical south Indian Ocean might act as a precondition for the development of the MCT variability since the peak phase of IOSD occurs during JFM when the MCT is strongest. Monthly composites of the SST anomalies show that weak MCT years are associated with warm SST anomalies in the southern Mozambique Channel and to the south of Madagascar from September onward.

On the other hand, MCThgt and NINO34 are significantly correlated from lag $=-9$ months to lag $=2$ months (Fig. 7b). Such correlation is expected given the strong atmospheric teleconnection between tropical Pacific and the Indian Ocean and the evolution of large-scale pressure anomalies across the Indian Ocean and southern Africa during the various phases of ENSO (Reason et al. 2000), consistent with a Matsuno-Gill response (Matsuno 1966; Gill 1980) response of the circulation to tropical SST forcing. During La Niña summers, negative geopotential height anomalies occur over the channel (Reason et al. 2000) but this does not necessarily mean that a closed cyclone occurs there. For instance, the years of 1996, 1999, and 2000 are classified as La Niña years with negative geopotential height anomaly in the southwestern Indian Ocean but they do not show a clear MCT in the channel. Thus, negative anomalies in MCThgt could also be a response to large-scale teleconnections as in La Niña, or an amplified trough by external forcing.

Given the strong impacts of SAM on regional climate during JFM (Gillett et al. 2006), the correlation with both MCT indices is perhaps not unexpected. From lag $=-2$ months to lag $=2$ months, both MCT indices show significant correlation with SAM, except at lag $=0$ where $r=0.27$ for MCTrv-SAM and $r=0.04$ for 

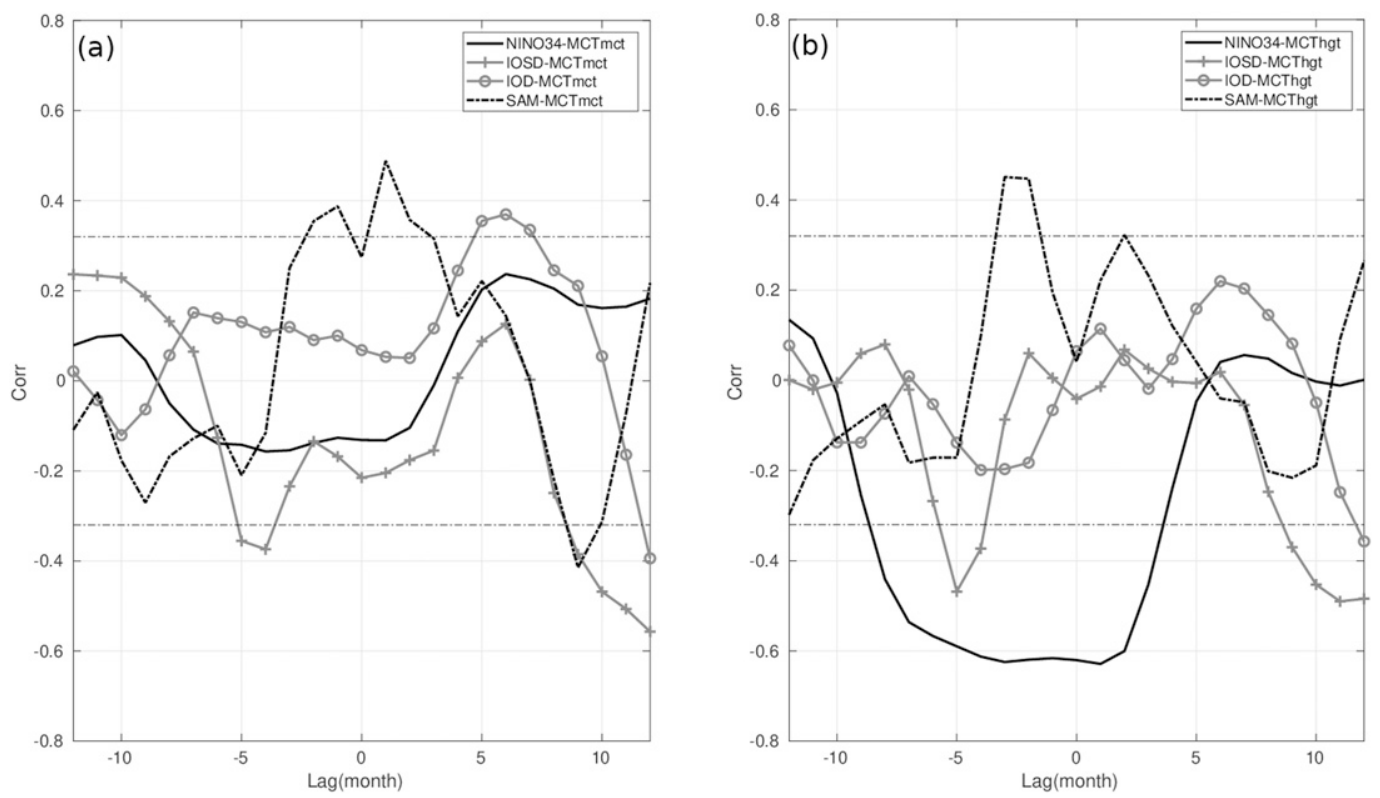

FIG. 7. (a) Lead-lag correlation between MCTrv and NINO34, IOSD, IOD, and SAM. The black dash-dotted lines show the threshold value for $95 \%$ statistical significance correlation. (b) As in (a), but using the MCThgt index. The MCT indices are calculated for JFM.

MCThgt-SAM (Figs. 7a,b). The positive correlations during this period are consistent with the weakening of the midlatitude westerlies and southward shift of the $\mathrm{MH}$ during the positive phase of the SAM, which would lead to stronger easterlies impacting on the mountains of Madagascar during JFM.

\section{e. Links between the MCT and regional rainfall}

In this section, a composite analysis is used to investigate the link between the MCT and regional rainfall, based on the MCTrv index during JFM. Individual strong MCT years show dipole-like rainfall pattern anomalies, both in CHIRPS and CMAP, in which a widespread deficit in JFM rainfall is seen over most of mainland southern Africa while the Mozambique Channel, parts of coastal Mozambique, and Madagascar are characterized by a significant increase in rainfall (Figs. 8a,c). In particular, a significant decrease in rainfall extending diagonally from northern Angola to southern Mozambique is apparent when the MCT is unusually intense. The maximum in negative rainfall anomaly (up to $2 \mathrm{~mm} \mathrm{day}^{-1}$ ) occurs over southern Mozambique, northern South Africa, and Zimbabwe. This value represents a reduction of up to about $180 \mathrm{~mm}$ during the late summer, which is substantial given that the annual mean rainfall in parts of this region is only $300-400 \mathrm{~mm}$. Interestingly a significant decrease in rainfall is also seen farther north, around Lake Victoria and northern Tanzania. On the other hand, enhanced rainfall of up to $3 \mathrm{mmday}^{-1}$ is evident in
Madagascar (except the southwestern part of the island) and northern coastal Mozambique. Such a rainfall dipole is a known feature of southern African rainfall (e.g., Jury 1992; Washington 1999; Mutai et al. 1998) in which wet summers on the mainland and dry summers in Madagascar are associated with anomalous penetration of the cross equatorial northeasterly flow into the subcontinent (Hachigonta and Reason 2006; Washington and Preston 2006; Kijazi and Reason 2009; Randriamahefasoa and Reason 2017). Wet summers in Madagascar are accompanied by enhanced monsoon northwesterlies flowing toward the island (Fauchereau et al. 2009; Jury et al. 2009). Nevertheless, the mechanism responsible for such a dipole is not fully understood and perhaps such a lack of understanding is part of the causes for the persisting large rainfall biases over southern Africa in climate models (e.g., Munday and Washington 2017, 2018). In addition, the ITCZ over the tropical western Indian Ocean is shifted to the south during strong MCT summers.

When the same analysis is repeated with the MCThgt index (but using $0.75 \sigma$ as threshold to define the anomalous summers since its variability is weaker than that of MCTrv), then the same rainfall anomaly patterns are found once the strong ENSO years have been removed. In the following, we will only present the composites from MCTrv given that the two indices yield essentially the same results. Although the strong MCT years include two La Niña summers $(1989,2012)$ when positive rainfall anomalies are generally expected over southern Africa 

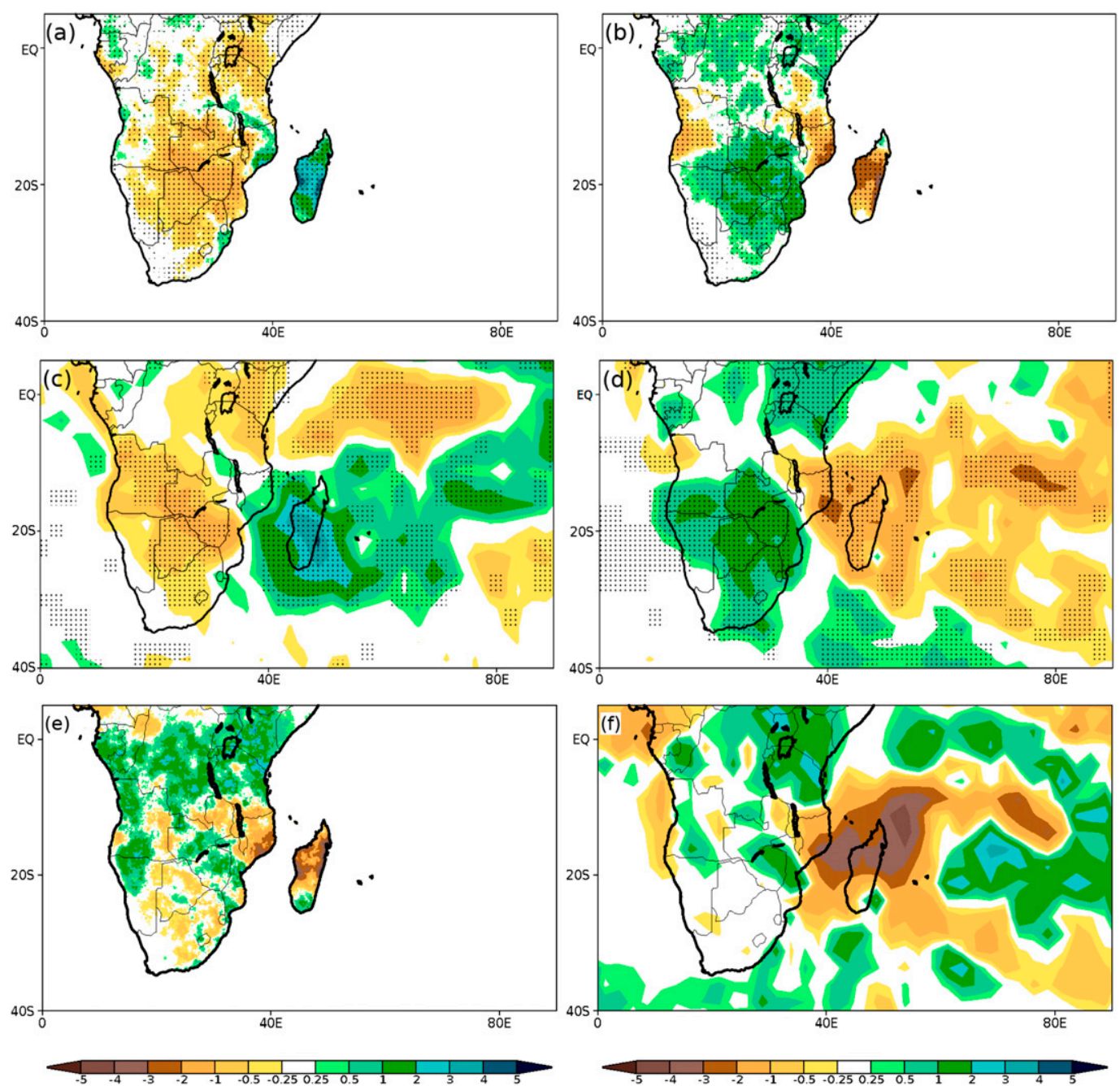

FIG. 8. Composite anomaly of CHIRPS precipitation $\left(\mathrm{mm} \mathrm{day}^{-1}\right)$ during (a) strong and (b) weak MCT years. (c),(d) As in (a) and (b), but using CMAP precipitation $\left(\mathrm{mm} \mathrm{day}^{-1}\right)$. Composites are calculated for JFM. Stippling shows significance at or above the $95 \%$ confidence level using a two-tailed nonparametric Monte Carlo bootstrap statistical significance test. (e),(f) CHIRPS and CMAP respective precipitation anomalies for JFM 1990.

(Lindesay 1988; Reason et al. 2000), it appears that the large areas of decreased rainfall are likely to be at least partly due to the effect of the anomalously strong MCT occurring then.

The composite anomaly in 850-hPa geopotential height (Fig. 9a) shows a strong cyclonic anomaly over the Mozambique Channel extending southward over the southwest Indian Ocean, which is favorable for tropical-extratropical cloud band development (Fauchereau et al. 2009; Hart et al. 2013, 2010; Harrison 1984) over the ocean rather than over the land. Continent-based cloud bands typically extend from the AL region toward the southeast coast of South Africa and out into the southwest Indian Ocean. Here the pattern is the same but the position is shifted toward the east over Madagascar and the Indian Ocean, suggesting a link between MCT strength and the cloud band location.
Although a weaker cyclonic anomaly is also seen in southern Angola, the presence of a strong high pressure anomaly due south of the subcontinent weakens the frontal activity there (and hence the midlatitude input to the cloud bands), inhibits the transport of moist marine air onto the land, and thus leads instead to cloud band development over the ocean.

Figure 9c displays the composite anomaly in $850-\mathrm{hPa}$ moisture transport and the vertically integrated flux divergence for strong MCT summers. In addition to the cyclonic circulation anomaly over the Mozambique Channel, strong MCT years are associated with westerly anomalies over northern Mozambique and Zambia, strengthened northwest monsoonal flow toward northern Madagascar, and enhanced integrated moisture flux convergence over this island and the Mozambique Channel. These westerlies feed the cyclone anomaly from its northern boundary, 

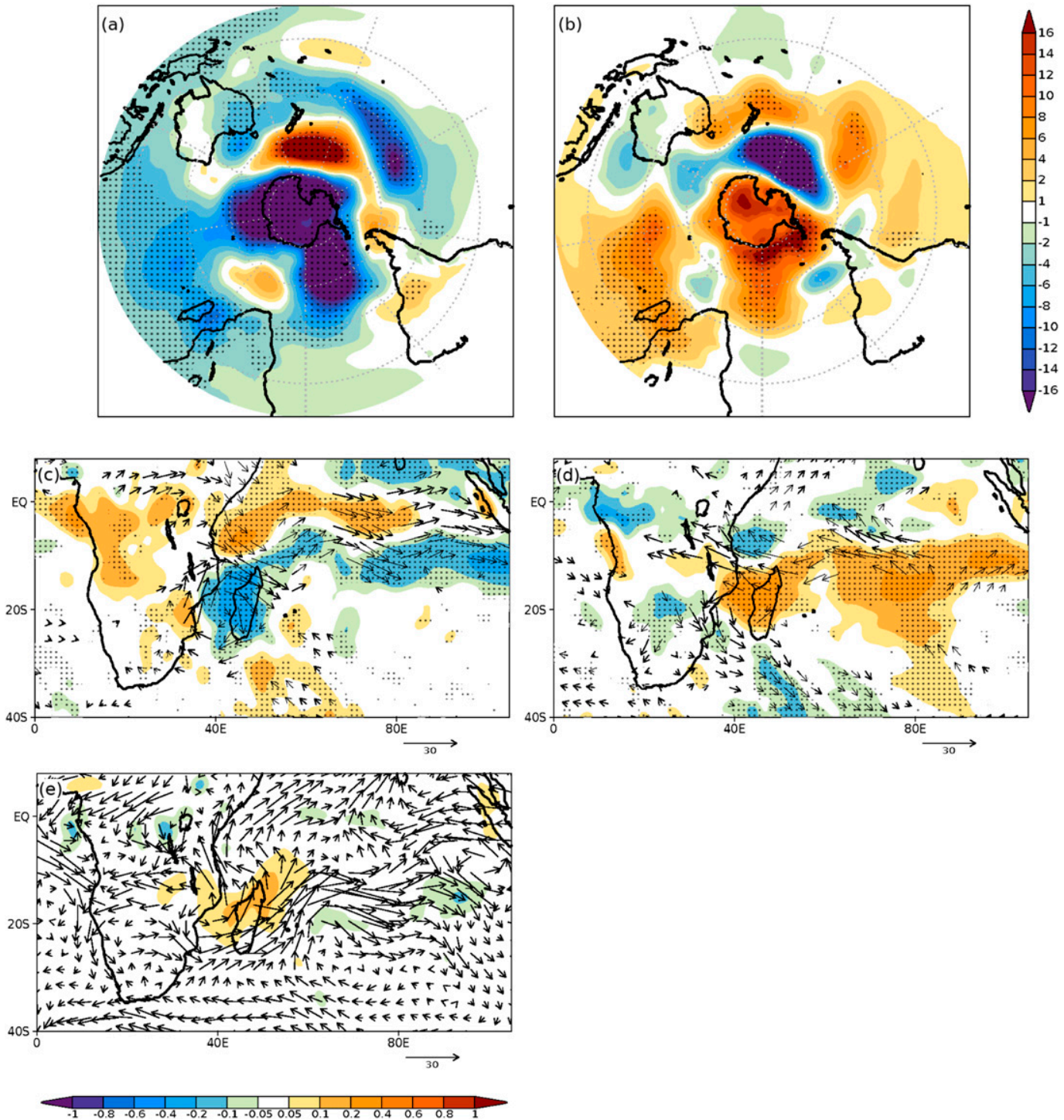

FIG. 9. (a)-(d) As in Figs. 8a-d, but depicting the 850-hPa geopotential height (shaded; m) in (a) and (b) and showing moisture flux (vectors) and vertically integrated divergence (shaded; $\mathrm{kg} \mathrm{kg}^{-1} \mathrm{~m} \mathrm{~s}^{-1}$ ) in (c) and (d) from ERA-Interim. Only significant moisture flux anomalies are shown by the arrows. Stippling shows significance at or above the $95 \%$ confidence level using a two-tailed nonparametric Monte Carlo bootstrap statistical significance test for the (e) vertically integrated divergence showing moisture flux (vectors) and vertically integrated divergence for JFM 1990.

transporting moist air to northern Mozambique and Madagascar, where anomalous convergence is taking place. Overall these conditions are favorable for increased rainfall in these regions (Fig. 8c). The anomalous westerlies also imply reduced transport of moist air from the Indian Ocean toward the subcontinent (i.e., to the mainland source region of cloud bands), which helps explain the rainfall deficit over most of southern Africa. On the southern side of the cyclonic feature in the Mozambique Channel, anomalous southeasterly flux from the southwest Indian Ocean feeds into the circulation. Since the cyclonic anomaly is located over the channel and Madagascar, the moisture transported by the southeasterlies is trapped within this feature and advected away from the mainland and toward the channel and Madagascar, where anomalous uplift is also present (not shown).

An increase in total cloud cover and a decrease in OLR, stretching from northern Mozambique across the channel and Madagascar toward the open southwest Indian Ocean occurs during strong MCT summers (Figs. 10a,c). This pattern indicates enhanced convection over the ocean and Madagascar in a cloud band orientation, resulting in increased rainfall there. The opposite pattern occurs over the mainland where a decrease in cloud cover 

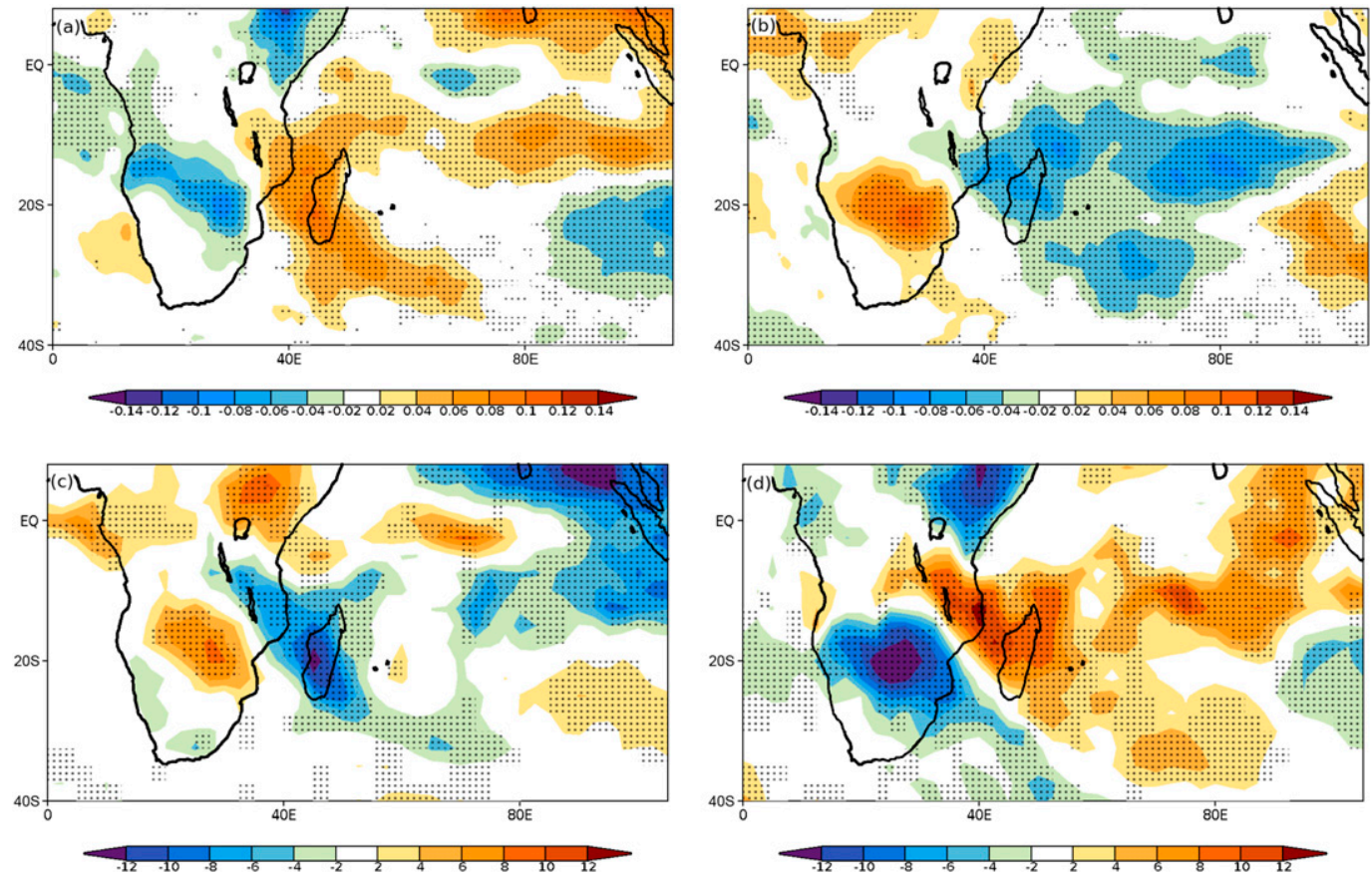

FIG. 10. As in Figs. 9a-d, but showing total cloud cover in (a) and (b) and the OLR in (c) and (d) from NCAR.

and increase in OLR is evident (i.e., less convection). The diagonally extended OLR anomalies are very similar in shape to the tropical-extratropical cloud bands, reinforcing the suggested link between MCT strength and the cloud bands. The dipole anomaly in the OLR also indicates an eastward shift of the convective activity away from the mainland. Moreover, the SST composite anomaly pattern shows cooling along the eastern African coast during strong MCT years (Fig. 4a), consistent with the increased total cloud cover, while the cold SST anomaly over the channel is also caused by the upwelled cold water from the cyclonic circulation. A northwest-southeast diagonally oriented cold SST anomaly is also seen from the southern Mozambique Channel to the southwest Indian Ocean, which is unfavorable for rainfall over the mainland (Walker 1990; Reason and Mulenga 1999).

For weak MCT summers, the rainfall composite anomaly (Figs. 8b,d) is roughly opposite to that for the strong case. A dipole-like pattern where an increase in rainfall, up to $3 \mathrm{~mm} \mathrm{day}^{-1}$, occurs over southern Mozambique, Zimbabwe, Botswana, and the Limpopo basin, while a rainfall deficit is seen in northern Mozambique and most of Madagascar (Figs. 8b,d). It is worth noting that the weak MCT years considered here include three summers with IOSD-type SST anomalies in the south Indian Ocean, and hence the rainfall anomaly over land could be expected to be positive (Behera and Yamagata 2001; Reason 2001, 2002). By looking separately at the summer of 1990 (anomalously weak MCT and neutral
IOSD), a decrease in rainfall is still seen in Madagascar but the increase in rainfall over mainland southern Africa is more restricted to the northern part of the domain over northern Tanzania and Kenya (Figs. 8e,f). During weak MCT years, the ITCZ over western Indian Ocean is placed north of its climatological position.

The composite anomaly of the 850-hPa geopotential height for weaker MCT summers shows a high pressure anomaly covering most of the Indian Ocean south of the equator (Fig. 9b). The anomaly is particularly strong in the Mozambique Channel as well as in the Mascarene high area. While the stronger $\mathrm{MH}$ also occurs during positive IOSD summers, other circulation features are different. A weak low pressure anomaly is seen in the western part of the subcontinent and the southwestern Indian Ocean, which could be favorable for cloud band development across the land and increased rainfall (Figs. 8b,d). The high pressure anomaly in the $\mathrm{MH}$ region transports more moist marine air toward tropical southern Africa. Enhanced easterlies from the tropical Indian Ocean thus strengthen the northern boundary of the anticyclonic anomaly in the Mozambique Channel, which then penetrates into northern Mozambique and Zambia, feeding into the source region for cloud bands (Harrison 1984; Washington and Todd 1999; Fauchereau et al. 2009; Hart et al. 2010, 2013; Manhique et al. 2011, 2015; Washington and Todd 1999). Studies have found that this part of the tropical Indian Ocean is a major moisture source for southern African rainfall (e.g., Mason 1995; Reason et al. 
2006). Increased moisture transport from the area therefore triggers the increase in rainfall over mainland. The anticyclonic anomaly over the Mozambique Channel also brings moisture into the mainland, transporting it southward where increased convergence takes place (Fig. 9d). The anomalous moisture flux divergence and subsidence over Madagascar and the Mozambique Channel (Fig. 9d) are in agreement with the decrease in rainfall in these areas. Farther to the north, the NE monsoon is weakened, indicating a decrease in moisture transported southward from the equatorial region. The weakening of the NE monsoon as well as the strong divergence over Madagascar is also apparent for the year 1990 (Fig. 9e), while the convergence over the mainland is relatively weak.

Furthermore, a northwest-southeast band of increased total cloud cover and decreased OLR are displayed over the subcontinent during weak MCT years, while the opposite occurs in northern Mozambique stretching to the east of Madagascar (Figs. 8b,d), consistent with more (less) cloud band development and rainfall over the mainland (Madagascar and the neighboring ocean). These signals are also in agreement with the warm SST anomaly in southwestern Indian Ocean (Fig. 5), which is favorable for increased rainfall over mainland.

\section{Summary and discussion}

This study has described the annual cycle and interannual variability of the Mozambique Channel trough, as well as its influence on southern African rainfall. The trough first becomes evident in the core of the austral summer (December), when it continues to strengthen until reaching its maximum intensity in February, after which it gradually weakens and is no longer present by the start of the austral winter (May). The timing of the peak intensity in MCT is associated with a southward shift of the ITCZ over the Mozambique Channel, the maximum SST over the channel, and the southeastward move of subtropical Mascarene high. The trough is also strengthened by the cross-equatorial NE monsoon, which curves as a northwesterly flow toward northern Madagascar.

The trough exhibits considerable interannual variability, which is dominated by anomalous moist convection occurring in the Mozambique Channel. The MCT variability is associated with the location of the warm SST anomaly pattern in the south Indian Ocean during IOSD years. Positive SST anomalies in the Mozambique Channel and near southern Africa weaken the trough, whereas the MCT is stronger if the warm anomaly is shifted toward the center or east of the basin. The MCT is also significantly correlated to the latitudinal extension of the northern border of the $\mathrm{MH}$, in which a southward shift of the border leads to a stronger MCT. In addition, strong cross-equatorial NE monsoon curving toward northern Madagascar strengthens the MCT. At zero lag, the variability of the vortex that forms in the MCT area tends to be independent of the large-scale modes of climate variability as well as the regional circulation. The lagged significant correlation with SAM indicates a possible delayed effect of the latitudinal extent of the westerly winds over the Southern Ocean on the MCT. However, the lagged correlation with IOSD suggests a preconditioning of the MCT by the temperature gradient in the south Indian Ocean. On the other hand, the strength of the MCT (as measured by its geopotential height at the 850-hPa level) is strongly driven by ENSO and therefore linked to the Angola low and the Botswana high. However, the link between ENSO and these regional circulations is nonlinear and some neutral ENSO years (e.g., 1982, 1984, 1994) also show strong MCT and strong BH and/or AL conditions during summer.

The physical mechanisms through which the MCT influences southern African interannual rainfall variability are argued as follows. During strong MCT years, anomalous cyclonic circulation stretches from the Mozambique Channel southeastwards well into the mid- or even high-latitude south Indian Ocean, impacting the key moisture transport corridors. The resultant anomalous moisture flux and uplift over Madagascar through stronger convection favor the formation of oceanic cloud bands extending from Mozambique to the southwest Indian Ocean. The change in location of these cloud bands, from being continental to oceanic, results in an increase in rainfall in northern Mozambique, Madagascar, and over the adjacent ocean. Increased cloud cover there then leads to a decrease in SST (through reduced insolation) within the Mozambique Channel and the northern Agulhas Current area, in addition to the cold SST anomaly triggered by the cyclonic circulation upwelled cold water in the channel. The stronger cyclonic circulation in a strong MCT also draws moisture into the system away from the southern African mainland and retains it, thus amplifying the decrease in rainfall over the subcontinent.

Farther to the north, during years with strong MCT, the moisture transported by the cross-equatorial NE monsoon curves as a northwesterly flow toward northern Madagascar rather than penetrating into the mainland, which then amplifies the rainfall increase in northern Mozambique and Madagascar, with a decrease over the subcontinent. In fact, the cross-equatorial NE flow is already noted as being important moisture source for southern Africa (D'Abreton and Tyson 1995; Washington and Preston 2006). Munday and Washington (2018) suggest that coupled models with high precipitation rates over southern Africa tend to have stronger northeasterly moisture transport penetrating farther inland rather than curving toward northern Madagascar. In this study, it is found that weak penetration of the NE monsoon over 
the land is associated with a strong MCT that draws the moisture away from mainland. This anomalous moisture transport is linked to the deficit in rainfall not only in southern Africa but also over Kenya and Tanzania.

The influence of a weak MCT on rainfall is not exactly the opposite of that of strong events. This is possibly due to most weak MCT events occurring in summers with a strong IOSD. However, this does not imply a linear relationship between MCT and IOSD. In fact, 1982 consists of a strong MCT and positive IOSD year, whereas 2012 is characterized by a strong MCT with negative IOSD. The relationships between the MCT and the IOSD depend on the location of the warm SST pole in the south Indian Ocean. The increase in rainfall over the mainland during weak MCT years is caused by the anomalous moisture transported from warm SST anomalies in the subtropical western Indian Ocean toward the source region of the cloud bands. On the other hand, the decrease in rainfall over Madagascar, the Mozambique Channel, and northern Mozambique is due to the subsidence associated with the enhanced $\mathrm{MH}$ and the decrease in cloud cover and convection in these areas.

The MCT is located in between two well-known sources of moisture for southern Africa (the NE monsoon and the easterly flow associated with the Mascarene high) during summer and appears to modulate the amount of moisture transported from these sources toward the African continent. Here, it is shown that a better understanding of the MCT brings an additional insight into the climate variability of the region and could be useful in any efforts to improve seasonal forecasts of southern African summer rainfall. Thus, in addition to monitoring the state of ENSO, SAM, and the IOSD, climate prediction and seasonal forecasting communities should therefore be encouraged to pay more attention to variability in the strength and location of the MCT.

Acknowledgments. This work was supported by NERC (Natural Environment Research Council), as part of the UMFULA project (NE/M020223/1) funded by the FCFA (Future Climate for Africa) program. Support for this study has also been provided by the University of Cape Town, South Africa.

\section{REFERENCES}

Barimalala, R., F. Desbiolles, R. C. Blamey, and C. Reason, 2018: Madagascar influence on the South Indian Ocean Convergence Zone, the Mozambique Channel Trough and southern African rainfall. Geophys. Res. Lett., 45, 11380-11 389, https:// doi.org/10.1029/2018GL079964.

Behera, S. K., and T. Yamagata, 2001: Subtropical SST dipole events in the southern Indian Ocean. Geophys. Res. Lett., 28, 327-330, https://doi.org/10.1029/2000GL011451.

Blamey, R. C., S. R. Kolusu, P. Mahlalela, M. Todd, and C. J. C. Reason, 2018: The role of regional circulation features in regulating El Niño climate impacts over southern Africa: A comparison of the 2015/2016 drought with previous events. Int. J. Climatol., 38, 4276-4295, https://doi.org/10.1002/joc.5668.

Cook, C., C. Reason, and B. Hewitson, 2004: Wet and dry spells within particularly wet and dry summers in the South African summer rainfall region. Climate Res., 26, 17-31, https://doi. org/10.3354/cr026017.

Cook, K. H., 2000: The South Indian convergence zone and interannual rainfall variability over southern Africa. J. Climate, 13, 3789-3804, https://doi.org/10.1175/1520-0442(2000)013<3789: TSICZA $>2.0 . \mathrm{CO} ; 2$.

Crétat, J., B. Pohl, B. Dieppois, S. Berthou, and J. Pergaud, 2019: The Angola Low: Relationship with southern African rainfall and ENSO. Climate Dyn., 52, 1783-1803, https://doi.org/ 10.1007/s00382-018-4222-3.

D'Abreton, P. C., and P. D. Tyson, 1995: Divergent and nondivergent water vapour transport over southern Africa during wet and dry conditions. Meteor. Atmos. Phys., 55, 47-59, https://doi.org/10.1007/BF01029601.

Dee, D. P., and Coauthors, 2011: The ERA-Interim reanalysis: Configuration and performance of the data assimilation system. Quart. J. Roy. Meteor. Soc., 137, 553-597, https://doi.org/10.1002/qj.828.

Desbiolles, F., R. Blamey, S. Illig, R. James, R. Barimalala, L. Renault, and C. Reason, 2018: Upscaling impact of wind/sea surface temperature mesoscale interactions on southern Africa austral summer climate. Int. J. Climatol., 38, 4651-4660, https://doi.org/10.1002/joc.5726.

Driver, P., and C. J. C. Reason, 2017: Variability in the Botswana High and its relationships with rainfall and temperature characteristics over southern Africa. Int. J. Climatol., 37, 570 581, https://doi.org/10.1002/joc.5022.

— B. Abiodun, and C. J. C. Reason, 2019: Modelling the precipitation response over southern Africa to the 2009-2010 El Niño using a stretched grid global atmospheric model. Climate Dyn., 52, 3929-3949, https://doi.org/10.1007/S00382-018-4362-5.

Fauchereau, N., B. Pohl, C. J. C. Reason, M. Rouault, and Y. Richard, 2009: Recurrent daily OLR patterns in the southern Africa/southwest Indian Ocean region, implications for South African rainfall and teleconnections. Climate Dyn., 32, 575-591, https://doi.org/10.1007/s00382-008-0426-2.

Funk, C., and Coauthors, 2015: The Climate Hazards Infrared Precipitation with Stations-A new environmental record for monitoring extremes. Sci. Data, 2, 150066, https://doi.org/ 10.1038/sdata.2015.66.

Gill, A. E., 1980: Some simple solutions for heat-induced tropical circulations. Quart. J. Roy. Meteor. Soc., 106, 447-462, https:// doi.org/10.1002/qj.49710644905.

Gillett, N. P., T. D. Kell, and P. D. Jones, 2006: Regional climate impacts of the Southern Annular Mode. Geophys. Res. Lett., 33, L23704, https://doi.org/10.1029/2006GL027721.

Hachigonta, S., and C. Reason, 2006: Interannual variability in dry and wet spell characteristics over Zambia. Climate Res., 32, 49-62, https://doi.org/10.3354/cr032049.

Harrison, M. S. J., 1984: A generalized classification of South African summer rain-bearing synoptic systems. J. Climatol., $\mathbf{4}$, 547-560, https://doi.org/10.1002/joc.3370040510.

Hart, N. C. G., C. J. C. Reason, and N. Fauchereau, 2010: Tropicalextratropical interactions over southern Africa: Three cases of heavy summer season rainfall. Mon. Wea. Rev., 138, 26082623, https://doi.org/10.1175/2010MWR3070.1.

$\ldots,-$ and $\longrightarrow$ 2013: Cloud bands over southern Africa: Seasonality, contribution to rainfall variability and modulation by the MJO. Climate Dyn., 41, 1199-1212, https://doi.org/ 10.1007/s00382-012-1589-4. 
Howard, E., and R. Washington, 2018: Characterizing the synoptic expression of the Angola low. J. Climate, 31, 7147-7165, https://doi.org/10.1175/JCLI-D-18-0017.1.

Jury, M. R., 1992: A climatic dipole governing the interannual variability of convection over the SW Indian Ocean and SE Africa region. Trends Geophys. Res., 1, 165-172.

- S. Chiao, and E. W. Harmsen, 2009: Mesoscale structure of trade wind convection over Puerto Rico: Composite observations and numerical simulation. Bound.-Layer Meteor., 132, 289-313, https://doi.org/10.1007/s10546-009-9393-3.

Kijazi, A., and C. Reason, 2009: Analysis of the 1998 to 2005 drought over the northeastern highlands of Tanzania. Climate Res., 38, 209-223, https://doi.org/10.3354/cr00784.

Lazenby, M., M. Todd, and Y. Wang, 2016: Climate model simulation of the South Indian Ocean convergence zone: Mean state and variability. Climate Res., 68, 59-71, https://doi.org/10.3354/cr01382.

Liebmann, B., and C. A. Smith, 1996: Description of a complete (interpolated) outgoing longwave radiation dataset. Bull. Amer. Meteor. Soc., 77, 1275-1277.

Lindesay, J. A., 1988: South African rainfall, the Southern Oscillation and a Southern Hemisphere semi-annual cycle. J. Climatol., 8, 17-30, https://doi.org/10.1002/joc.3370080103.

Manatsa, D., and C. Reason, 2017: ENSO-Kalahari Desert linkages on southern Africa summer surface air temperature variability. Int. J. Climatol., 37, 1728-1745, https://doi.org/10.1002/joc.4806.

Manhique, A. J., C. J. C. Reason, L. Rydberg, and N. Fauchereau, 2011: ENSO and Indian Ocean sea surface temperatures and their relationships with tropical temperate troughs over Mozambique and the southwest Indian Ocean. Int. J. Climatol., 31, 1-13, https://doi.org/10.1002/joc.2050.

,-- B. Silinto, J. Zucula, I. Raiva, F. Congolo, and A. F. Mavume, 2015: Extreme rainfall and floods in southern Africa in January 2013 and associated circulation patterns. Nat. Hazards, 77, 679-691, https://doi.org/10.1007/s11069-015-1616-y.

Marshall, G. J., 2003: Trends in the southern annular mode from observations and reanalyses. J. Climate, 16, 4134-4143, https:// doi.org/10.1175/1520-0442(2003)016<4134:TITSAM > 2.0.CO;2.

Mason, S. J., 1995: Sea-surface temperature-South African rainfall associations, 1910-1989. Int. J. Climatol., 15, 119-135, https://doi.org/10.1002/joc.3370150202.

Matsuno, T., 1966: Quasi-geostrophic motions in the equatorial area. J. Meteor. Soc. Japan, 44, 25-43.

Morioka, Y., K. Takaya, S. K. Behera, and Y. Masumoto, 2015: Local SST impacts on the summertime Mascarene high variability. J. Climate, 28, 678-694, https://doi.org/10.1175/JCLI-D-14-00133.1.

Munday, C., and R. Washington, 2017: Circulation controls on southern African precipitation in coupled models: The role of the Angola low. J. Geophys. Res. Atmos., 122, 861-877, https:// doi.org/10.1002/2016JD025736.

_ , and _ 2018: Systematic climate model rainfall biases over southern Africa: Links to moisture circulation and topography. J. Climate, 31, 7533-7548, https://doi.org/10.1175/JCLI-D-18-0008.1.

Mutai, C.C., M. N. Ward, and A. W. Colman, 1998: Towards the prediction of the East Africa short rains based on seasurface temperature-atmosphere coupling. Int. J. Climatol. 18, 975-997, https://doi.org/10.1002/(SICI)1097-0088(199807) 18:9<975::AID-JOC259>3.0.CO;2-U.

Nicholson, S. E., and J. Kim, 1997: The relationship of the El NiñoSouthern Oscillation to African rainfall. Int. J. Climatol., 17, 117-135, https://doi.org/10.1002/(SICI)1097-0088(199702)17: $2<117::$ AID-JOC84>3.0.CO;2-O.

Pascale, S., B. Pohl, S. Kapnick, and H. Zhang, 2019: On the Angola low interannual variability and its role in modulating
ENSO effects in southern Africa. J. Climate, 32, 4783-4803, https://doi.org/10.1175/JCLI-D-18-0745.1.

Randriamahefasoa, T. S. M., and C. J. C. Reason, 2017: Interannual variability of rainfall characteristics over southwestern Madagascar. Theor. Appl. Climatol., 128, 421-437, https://doi.org/ 10.1007/s00704-015-1719-0.

Rayner, N. A., D. E. Parker, E. B. Horton, C. K. Folland, L. V. Alexander, D. P. Rowell, E. C. Kent, and A. Kaplan, 2003: Global analyses of sea surface temperature, sea ice, and night marine air temperature since the late nineteenth century. J. Geophys. Res., 108, 4407, https://doi.org/10.1029/2002JD002670.

Reason, C. J. C., 2001: Subtropical Indian Ocean SST dipole events and southern African rainfall. Geophys. Res. Lett., 28, 22252227, https://doi.org/10.1029/2000GL012735.

_ 2002: Sensitivity of the southern African circulation to dipole sea-surface temperature patterns in the south Indian Ocean. Int. J. Climatol., 22, 377-393, https://doi.org/10.1002/joc.744. 2016: The Bolivian, Botswana, and Bilybara Highs and Southern Hemisphere drought/floods. Geophys. Res. Lett., 43, 1280-1286, https://doi.org/10.1002/2015GL067228.

, and H. Mulenga, 1999: Relationships between South African rainfall and SST anomalies in the southwest Indian Ocean. Int. J. Climatol., 19, 1651-1673, https://doi.org/10.1002/(SICI) 1097-0088(199912)19:15<1651::AID-JOC439>3.0.CO;2-U. , and M. Rouault, 2002: ENSO-like decadal variability and South African rainfall. Geophys. Res. Lett., 29, 1638, https:// doi.org/10.1029/2002GL014663.

_ - R. J. Allan, J. A. Lindesay, and T. J. Ansell, 2000: ENSO and climatic signals across the Indian Ocean Basin in the global context: Part I, interannual composite patterns. Int. J. Climatol., 20, 1285-1327, https://doi.org/10.1002/1097-0088(200009)20: $11<1285::$ AID-JOC536>3.0.CO;2-R.

, W. Landman, and W. Tennant, 2006: Seasonal to decadal prediction of southern African climate and its links with variability of the Atlantic Ocean. Bull. Amer. Meteor. Soc., 87, 941-956, https://doi.org/10.1175/BAMS-87-7-941.

Rowell, D. P., 2013: Simulating SST Teleconnections to Africa: What is the state of the art? J. Climate, 26, 5397-5418, https:// doi.org/10.1175/JCLI-D-12-00761.1.

Saji, N. H., B. N. Goswami, P. N. Vinayachandran, and T. Yamagata, 1999: A dipole mode in the tropical Indian Ocean. Nature, 401, 360-363, https://doi.org/10.1038/43854.

Trenberth, K. E., and D. P. Stepaniak, 2001: Indices of El Niño evolution. J. Climate, 14, 1697-1701, https://doi.org/10.1175/ 1520-0442(2001)014<1697:LIOENO>2.0.CO;2.

Walker, N. D., 1990: Links between South African summer rainfall and temperature variability of the Agulhas and Benguela Current systems. J. Geophys. Res., 95, 3297, https://doi.org/ 10.1029/JC095iC03p03297.

Washington, R., 1999: Interannual and interdecadal variability of African rainfall. Ph.D. thesis, University of Oxford, 258 pp.

, and M. Todd, 1999: Tropical-temperate links in southern African and Southwest Indian Ocean satellite-derived daily rainfall. Int. J. Climatol., 19, 1601-1616, https://doi.org/10.1002/(SICI)10970088(19991130)19:14<1601::AID-JOC407>3.0.CO;2-0.

, and A. Preston, 2006: Extreme wet years over southern Africa: Role of Indian Ocean sea surface temperatures. J. Geophys. Res., 111, D15104, https://doi.org/10.1029/2005JD006724.

Xie, P., and P. A. Arkin, 1997: Global precipitation: A 17-year monthly analysis based on gauge observations, satellite estimates, and numerical model outputs. Bull. Amer. Meteor. Soc., 78, 25392558, https://doi.org/10.1175/1520-0477(1997)078<2539: GPAYMA $>2.0 . \mathrm{CO} ; 2$. 